ALCHEMY Jurnal Penelitian Kimia

Laman resmi: https://jurnal.uns.ac.id/alchemy

\title{
Pembuatan Ca-Mg-Al Hydrotalcite-like compound dari Brine Water untuk menjerap Cr(VI)
}

\author{
Eddy Heraldy*, Edi Pramono, Yohana Gita Aprillia \\ Program Studi Kimia, Fakultas Matematika dan Ilmu Pengetahuan Alam, Universitas Sebelas Maret, Jl. Ir. \\ Sutami 36A Surakarta, 57126, Jawa Tengah, Indonesia \\ * Corresponding author \\ E-mail: eheraldy@mipa.uns.ac.id \\ DOI: 10.20961/alchemy.15.1.27032.124-137
}

Received 16 January 2019, Accepted 22 February 2019, Published 01 March 2019

\begin{abstract}
ABSTRAK
Pembuatan Ca-Mg-Al hydrotalcite-like compound (HTlc) dengan metode kopresipitasi telah dilakukan. Hydrotalcite-like yang terbentuk dikarakterisasi dengan X-ray Diffraction (XRD), Fourier Transform Infra Red (FTIR), Surface Area Analyzer (SAA) dan digunakan sebagai adsorben Cr(VI). Hasil karakterisasi XRD menunjukkan adanya nilai $d 7,54 \AA$ pada sudut 2 theta $11,73^{\circ}$ yang merupakan ciri hydrotalcite dengan interlayer karbonat. Hasil ini diperkuat dengan adanya gugus hidroksi pada daerah bilangan gelombang IR sekitar $3441 \mathrm{~cm}^{-1}$ serta gugus karbonat pada $1361 \mathrm{~cm}^{-1}$. Proses adsorpsi $\mathrm{Cr}(\mathrm{VI})$ dengan menggunakan $\mathrm{Ca}-\mathrm{Mg}-\mathrm{Al}$ hydrotalcite-like menunjukkan kondisi optimum pada $\mathrm{pH} 3$ dan waktu kontak 20 menit. Kinetika adsoprsi $\mathrm{Cr}(\mathrm{VI})$ oleh $\mathrm{Ca}-\mathrm{Mg}$-Al hydrotalcite-like cenderung mengikuti persamaan kinetika pseudo second order dan isoterm adsorpsinya mengikuti model isoterm Langmuir. Kapasitas adsorpsi maksimum $\mathrm{Cr}(\mathrm{VI})$ menggunakan $\mathrm{Ca}-\mathrm{Mg}-\mathrm{Al}$ hydrotalcite-like lebih besar dibandingkan menggunakan hydrotalcite komersial. Pita spektra FTIR setelah adsorpsi Cr(VI) menunjukkan ion kromium terserap ke dalam Ca-Mg-Al hydrotalcite-like compound.
\end{abstract}

Kata kunci: adsorpsi, brine water, $\mathrm{Ca}-\mathrm{Mg}-\mathrm{Al}$ hydrotalcite-like compound, $\mathrm{Cr}(\mathrm{VI})$

\begin{abstract}
Synthesis of Ca-Mg-Al Hydrotalcite-like compound from Brine Water for $\mathrm{Cr}(\mathrm{VI})$ removal. The synthesis of Ca-Mg-Al hydrotalcite-like compound (Htlc) with a coprecipitation method had been done. Hydrotalcite-like product was characterized by X-ray diffraction (XRD), Fourier transform infra red (FTIR), surface area analyzer (SAA) and was used as an adsorbent of $\mathrm{Cr}(\mathrm{VI})$. The XRD characterization result indicates a value of $d 7.54 \AA$ at 2 theta $11.73^{\circ}$, which is a characteristic of hydrotalcite with carbonate interlayer. These results are confirmed by the presence of a hydroxy group at wavenumber of IR around 3441 $\mathrm{cm}^{-1}$ and carbonate groups in the $1361 \mathrm{~cm}^{-1}$. The adsorption of $\mathrm{Cr}(\mathrm{VI})$ using the Ca-Mg-Al hydrotalcite-like showed the optimum conditions at pH 3 and 20 minutes contact time. The adsorption kinetic of $\mathrm{Cr}(\mathrm{VI})$ by $\mathrm{Ca}-\mathrm{Mg}-\mathrm{Al}$ hydrotalcite-like tends to follow the pseudo second order equation and the adsorption isotherm tends to follow the Langmuir model. The maximum adsorption capacity of $\mathrm{Cr}(\mathrm{VI})$ using the $\mathrm{Ca}-\mathrm{Mg}-\mathrm{Al}$ hydrotalcite-like is greater than that of using commercial hydrotalcite. Morever, the FTIR spectra analyzed after $\mathrm{Cr}(\mathrm{VI})$ adsorption indicates that chromium ion was adsorbed into of $\mathrm{Ca}-\mathrm{Mg}$ - $\mathrm{Al}$ hydrotalcite-like compound.
\end{abstract}

Keywords: adsorption, brine water, $\mathrm{Ca}-\mathrm{Mg}$-Al hydrotalcite-like compound, $\mathrm{Cr}(\mathrm{VI})$ 


\section{PENDAHULUAN}

Indonesia dikenal juga sebagai suatu negara maritim. Hampir sebagian besar wilayah Indonesia adalah daerah perairan laut. Dengan sumber daya air laut yang tersedia melimpah, air laut berpotensi dijadikan sebagai salah satu alternatif sumber air bersih untuk industri maupun rumah tangga. Untuk keperluan industri, dalam proses desalinasi di PLTU, hanya $40 \%$ air laut dapat diubah menjadi air bersih, sedangkan $60 \%$ sisanya yang disebut brine water yang mengandung kadar garam tinggi akan dibuang kembali ke laut sebagai limbah. Dengan kata lain, bila satu unit proses desalinasi membutuhkan air laut sebanyak $350 \mathrm{~m}^{3} / \mathrm{jam}$, maka $200 \mathrm{~m}^{3} / \mathrm{jam}$ brine water yang telah mengandung logam alkali dan alkali tanah dalam konsentrasi yang tinggi dibuang begitu saja (Heraldy et al., 2012a).

Hydrotalcite (HT) dengan formula umum $\left[M^{2+}{ }_{1-x} M^{3+}{ }_{x}(\mathrm{OH})_{2}\right]^{x+}\left(\mathrm{A}^{n-}\right)_{x / n} \cdot m \mathrm{H}_{2} \mathrm{O}$, adalah suatu Layered Double Hydroxide (LDH) (Cavani et al., 1991, Heraldy et al., 2017), dimana $M^{2+}$ merupakan kation divalen, $M^{3+}$ adalah kation divalen, dan $A^{n-}$ sebagai anion penyeimbang. Nilai rasio molar $(x)$ adalah antara $0,2-0,33$ dan $m$ adalah jumlah $\mathrm{H}_{2} \mathrm{O}$ pada interlayer. Dengan formula HT atau LDH ini, kemungkinan pemanfaatan logam-logam kation bervalensi dua dan tiga untuk sintesis HT atau LDH sangat besar. Kameda et al. (2000) telah mensintesis Mg-Al hydrotalcite dari air laut buatan, sementara Heraldy et al. (2011) berhasil mensintesis $\mathrm{Mg} / \mathrm{Al}$ hydrotalcite-like compound (HTlc) dari brine water yang keberadaan ion kalsiumnya dihilangkan terlebih dahulu. Hal ini dilakukan oleh kedua peneliti tersebut karena beranggapan adanya ion kalsium dalam air laut buatan maupun brine water merupakan pengotor yang mampu menghambat terbentuknya kristal hydrotalcite. Akan tetapi, Gao et al. (2010) telah mengkombinasikan tiga senyawa murni $\mathrm{Ca}\left(\mathrm{NO}_{3}\right) \cdot 4 \mathrm{H}_{2} \mathrm{O}, \mathrm{Mg}\left(\mathrm{NO}_{3}\right)_{2} \cdot 6 \mathrm{H}_{2} \mathrm{O}$ dan $\mathrm{Al}\left(\mathrm{NO}_{3}\right)_{3} \cdot 9 \mathrm{H}_{2} \mathrm{O}$ sebagai komponen penyusun HTlc untuk membuat senyawa Ca-Mg-Al HTlc. Dengan demikian, dua logam alkali tanah yang terkandung pada brine water, yaitu $\mathrm{Ca}^{2+}$ dan $\mathrm{Mg}^{2+}$ dapat dimanfaatkan untuk sintesis HTlc. Menurut Heraldy et al. (2012a), ada tiga puncak utama penciri hydrotalcite-like yang juga merupakan ciri struktur berlapis (layered structure) yaitu pada 2 theta sekitar $11^{\circ}, 23^{\circ}$ dan $35^{\circ}$.

Hydrotalcite-like sering digunakan sebagai suatu penukar ion, prekursor katalis, fotokatalis atau prekursor untuk preparasi material anorganik, sediaan farmaka dan kosmetika (Kameda et al., 2000; Heraldy et al., 2012b). Selain itu, HTlc sering digunakan sebagai suatu adsorben (Heraldy et al., 2012a, 2015; Setshedi et al., 2012, Yang et al., 2010). Beberapa peneliti telah menggunakan HTlc sebagai suatu adsorben untuk mereduksi logam berat seperti $\mathrm{Cu}, \mathrm{Zn}, \mathrm{Cd}$ (Anirudhan and Suchithra, 2010) dan $\mathrm{Pb}$ 
(Setshedi et al., 2012). Dari keberadaan brine water yang melimpah serta potensi HTlc yang sangat baik sebagai adsorben, maka dilakukan penelitian tentang sintesis HTlc dan aplikasinya dalam adsorpsi logam berat $\mathrm{Cr}(\mathrm{VI})$ yang bersifat toksik dan karsinogenik.

\section{METODOLOGI PENELITIAN}

\section{Sintesis Ca-Mg-Al HTlc}

Sejumlah $\mathrm{AlCl}_{3} \cdot 6 \mathrm{H}_{2} \mathrm{O}$ ditambahkan ke dalam brine water dengan perbandingan mol $(\mathrm{Ca}+\mathrm{Mg}) / \mathrm{Al}=2$. Kemudian ditambahkan larutan $\mathrm{Na}_{2} \mathrm{CO}_{3} 0,1 \mathrm{M}$ hingga $\mathrm{pH}$ campuran \pm 10 lalu direfluks selama 60 menit dengan suhu $65-70{ }^{\circ} \mathrm{C}$. Setelah itu, larutan didiamkan sampai filtrat dan endapan terpisah. Kemudian diambil filtrat yang telah terpisah dari endapan (slurry), endapan ditambah akuades hingga 2 L lalu didiamkan hingga semalaman. Pada hari berikutnya, endapan dicuci dengan akuades secara berkala hingga bebas ion $\mathrm{Cl}^{-}$, tidak menimbulkan endapan berwarna putih ketika air cuciannya diteteskan larutan $\mathrm{AgNO}_{3}$. Slurry yang bebas ion $\mathrm{Cl}^{-}$di sentrifuge, lalu dioven pada suhu $105{ }^{\circ} \mathrm{C}$ selama 24 jam. Slurry kering (padatan) yang diperoleh digerus hingga halus.

\section{Karakterisasi}

Analisis logam $\mathrm{Ca}$ dan $\mathrm{Mg}$ pada brine water dilakukan menggunakan Atomic Absorption Spectrophotometer (AAS) Shimadzu AA 630-12. Padatan hydrotalcite dikarakterisasi menggunakan X-Ray Diffaction (XRD) Bruker D8 Advance. Analisis gugus fungsi menggunakan Fourier Transform Infra Red (FT-IR) Shimadzu IR Prestige-21 metode $\mathrm{KBr}$ dengan batas panjang gelombang $400-4000 \mathrm{~cm}^{-1}$. Analisis luas permukaan dan ukuran pori dengan Surface Area Analyzer (SAA) Quantachrome Nova Win 1200e dengan degassing selama 30 menit suhu $300{ }^{\circ} \mathrm{C}$.

\section{Desain Eksperimen Adsorpsi Batch}

\section{Penentuan waktu kontak optimum.}

Penentuan waktu kontak optimum adsorpsi Cr(VI) dilakukan pada variasi waktu kontak 5, 10, 15, 20, dan 25 menit pada pH optimumnya. Pada saat adsorpsi Cr(VI) menggunakan Ca-Mg-Al HTlc hasil sintesis, $\mathrm{pH}$ adsorpsi diatur pada $\mathrm{pH}$ 3. Setelah proses adsorpsi berakhir, larutan disaring dan filtratnya diukur absorbansinya menggunakan spektroskopi UV-Vis pada panjang gelombang maksimum $536 \mathrm{~nm}$.

\section{Studi kinetika adsorpsi.}

Data yang diperoleh dari variasi waktu kontak diplotkan pada model persamaan pseudo first order dan pseudo second order. Model persamaan kinetika pseudo first order menggunakan persamaan (1) yang merujuk dari Ho (2005) dan Heraldy et al. (2015). 


$$
\log \left(q_{e}-q_{t}\right)=\log q_{e}-\frac{k_{1} t}{2,303}
$$

dengan $k_{l}$ (1/menit) adalah konstanta laju pseudo order satu, $t$ adalah waktu (menit), $q_{e}$ (mg/g) adalah kapasitas adsorpsi dalam kesetimbangan dan $q_{t}(\mathrm{mg} / \mathrm{g})$ adalah kapasitas adsorpsi dalam waktu $t$, sedangkan model persamaan pseudo second order seperti persaman (2) berikut:

$$
\frac{t}{q_{t}}=\frac{1}{k_{2} \times q_{e}^{2}}+\frac{t}{q_{e}}
$$

dimana $k_{2}$ [g/(mg.menit)] adalah konstanta laju pseudo order dua.

\section{Penentuan isoterm adsorpsi.}

Penentuan isoterm adsorpsi $\mathrm{Cr}(\mathrm{VI})$ dilakukan pada variasi konsentrasi awal 50, 75, 100, 125 dan $150 \mathrm{mg} / \mathrm{L}$. Pada saat adsorpsi Cr(VI) menggunakan HTlc hasil sintesis $\mathrm{pH}$ adsorpsi diatur pada $\mathrm{pH} 3$ selama 20 menit. Setelah proses adsorpsi berakhir, larutan disaring dan filtratnya diukur absorbansinya menggunakan spektroskopi UV-Vis pada panjang gelombang maksimum $536 \mathrm{~nm}$.

Data yang diperoleh dari variasi konsentrasi awal diplotkan pada model persamaan Langmuir dan Freundlich. Model persamaan Langmuir seperti persamaan (3) berikut:

$$
\frac{c_{e}}{q_{e}}=\frac{c_{e}}{Q_{\max }}+\frac{1}{Q_{\max } \times \mathrm{k}_{\mathrm{L}}}
$$

dimana $c_{e}(\mathrm{mg} / \mathrm{L})$ adalah konsentrasi adsorbat dalam kesetimbangan, $Q_{\max }(\mathrm{mg} / \mathrm{g})$ adalah kapasitas adsorpsi maksimum, dan $k_{\mathrm{L}}(\mathrm{L} / \mathrm{mg})$ adalah konstanta adsorpsi Langmuir yang terkait dengan energi adsorpsi. Model persamaan Freundlich ditunjukkan seperti persamaan (4) di bawah ini.

$$
\log q_{e}=\log k_{F}+\frac{1}{n} \log c_{e}
$$

dimana $k_{F}(\mathrm{mg} / \mathrm{g})$ adalah konstanta Freundlich, dan $1 / n$ adalah faktor heterogenitas.

\section{HASIL DAN PEMBAHASAN}

\section{Sintesis Ca-Mg-Al HTlc}

Fase hydrotalcite dari Ca-Mg-Al HTlc dianalisis dengan membandingkan (d) basal spacing, $2 \theta$ senyawa hasil Ca-Mg-Al HTlc pada difraktogram XRD dengan data JCPDS Mg-Al hydrotalcite (\#890460) dan Ca-Al hydrotalcite (\#870493). Ciri utama dari Ca-MgAl hydrotalcite adalah adanya sudut difraksi pada $11,5^{\circ} ; 23,45^{\circ}$ dan $34,57^{\circ}$, sedangkan $61,9^{\circ}$ diketahui merupakan sudut difraksi dari anion antar lapisan berupa $\mathrm{CO}_{3}{ }^{2-}$ (Heraldy et al., 2015). Pada Gambar 1 terlihat difraktogram Ca-Mg-Al HTlc memiliki basal spasing yang 
mendekati JCPDS Mg-Al hydrotalcite dan JCPDS Ca-Al hydrotalcite yaitu $11,73^{\circ} ; 23,35^{\circ}$; $35,05^{\circ} ; 39,56^{\circ}$.

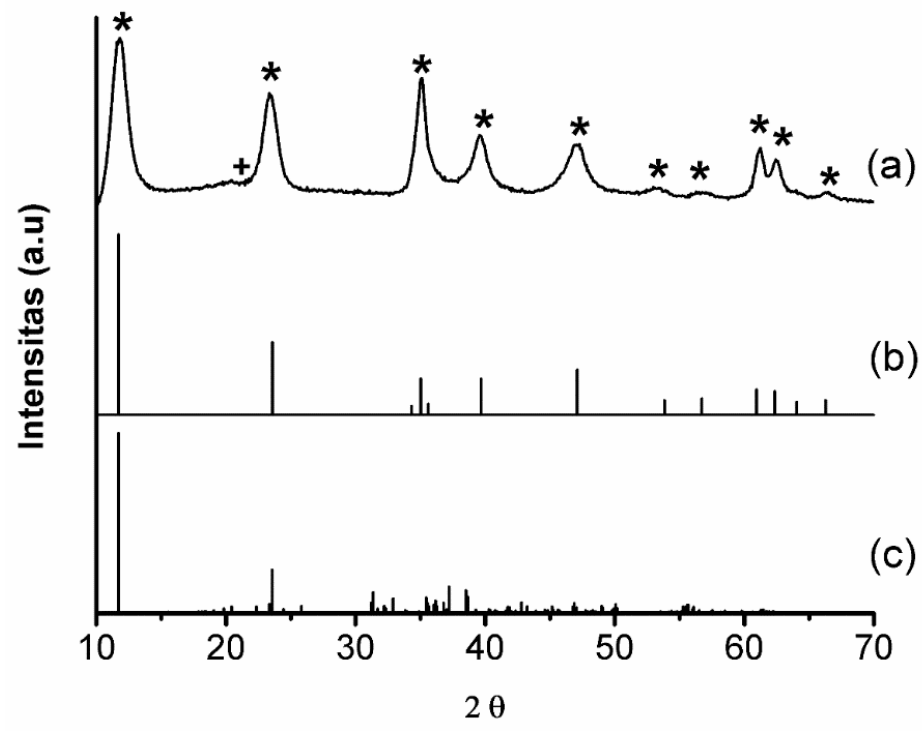

Gambar 1. Difraktogram XRD untuk (a) Ca-Mg-Al HTlc hasil sintesis, (b) Mg-Al hydrotalcite (\#890460) dan (c) Ca-Al hydrotalcite (\#870493).

Perbandingan nilai $d$ puncak-puncak difraktogram senyawa hasil sintesis dengan data $d$ JCPDS disajikan pada Tabel 1 .

Tabel 1. Perbandingan nilai $d$ antara JCPDS Mg-Al HT, JCPDS Ca-Al HT dengan Ca-MgAl-HTlc hasil sintesis.

\begin{tabular}{lcc}
\hline \multicolumn{1}{c}{ Keterangan } & $d(\AA)$ & 2 theta $\left(^{\circ}\right)$ \\
\hline \multirow{3}{*}{ JCPDS Mg-Al HT } & 7,59 & 11,65 \\
& 3,79 & 23,42 \\
& 2,53 & 35,45 \\
& 2,28 & 39,44 \\
\hline \multirow{2}{*}{ JCPDS Ca-Al HT } & 7,55 & 11,71 \\
& 3,78 & 23,54 \\
& 2,53 & 35,43 \\
Ca-Mg-Al HTlc (hasil & 2,27 & 39,61 \\
sintesis) & 7,54 & 11,73 \\
& 3,80 & 23,35 \\
& 2,56 & 35,05 \\
& 2,28 & 39,56 \\
\hline
\end{tabular}

Gambar 1 dan Tabel 1 menunjukkan bahwa $\mathrm{Ca}-\mathrm{Mg}-\mathrm{Al}-\mathrm{HTlc}$ hasil sintesis mempunyai nilai $d$ spacing yang mendekati nilai JCPDS Ca-Al HT yaitu pada $d=7,55$; 3,78 dan 2,27 A. Selain itu, Ca-Mg-Al HTlc hasil sintesis juga mempunyai nilai $d$ spacing yang mendekati nilai JCPDS Mg-Al HT yaitu pada $d=7,59 ; 3,78 ; 2,53$ dan 2,28 . Johnson and Glasser (2003) memperoleh $d$ spacing Mg-Al HT pada $d=7,56 ; 3,80 ; 2,58$; 
dan 2,31 Å. Menurut Heraldy et al. (2011) nilai refleksi bidang $d_{003}$ HT sintetis pada 7,58 $\AA$, merupakan ciri dari adanya interkalasi karbonat $\left(\mathrm{CO}_{3}{ }^{2-}\right)$ pada daerah interlayer. Dari hasil penelitian Heraldy et al. (2012a) ada tiga puncak utama pada nilai 2 theta sekitar 11,7; 23,6; dan $35,1^{\circ}$. Ketiganya merupakan ciri struktur berlapis (layered structure). Nilai $d \mathrm{Ca}$ $\mathrm{Mg}-\mathrm{Al} \mathrm{HTlc}$ hasil sintesis yang hampir sama dengan JCPDS Mg-Al dan $\mathrm{Ca}-\mathrm{Al}$ mengindikasikan telah terbentuk Ca-Mg-Al HTlc.

Data lain untuk mendukung pembuktian bahwa senyawa yang terbentuk adalah hydrotalcite (HT), yaitu dengan melakukan identifikasi gugus-gugus fungsi yang terkandung dalam senyawa hasil sintesis $\mathrm{Ca}-\mathrm{Mg}-\mathrm{Al} \mathrm{HTlc}$ dari brine water. Untuk menentukan gugus fungsi pada Ca-Mg-Al hydrotalcite, dilakukan analisis FTIR. Gugusgugus fungsi yang dominan menyusun $\mathrm{HT}$ adalah gugus fungsi hidroksi $(\mathrm{OH})$, ion karbonat $\left(\mathrm{CO}_{3}{ }^{2-}\right)$ serta ikatan logam oksidanya (M-O). Data hasil identifikasi gugus-gugus fungsi penyusun HT hasil sintesis dari brine water ditunjukkan pada Tabel 2 dan Gambar 2.

Tabel 2. Perbandingan Bilangan Gelombang Ca-Mg-Al HTlc hasil sintesis dengan referensi*.

\begin{tabular}{ccc}
\hline \multirow{2}{*}{ Gugus fungsi } & \multicolumn{2}{c}{ Bilangan Gelombang $\left(\mathrm{cm}^{-1}\right)$} \\
\cline { 2 - 3 } & Referensi* $^{*}$ & HTlc hasil sintesis \\
\hline Uluran O-H & $16300^{1} ; 3440^{3} ; 3450^{2,4} ; 3458^{5}$ & 3441 \\
Tekukan O-H & $1370^{2,4} ; 1352^{3} ; 1350^{4}$ & 1629 \\
Uluran $\mathrm{CO}_{3}{ }^{2-}$ & $680^{2} ; 670-690^{4}$ & 1361 \\
Tekukan $\mathrm{CO}_{3}{ }^{2-}$ & $400-600^{1} ; 445-553^{4}$ & 678 \\
Uluran M-O (M=Mg, Ca, Al) & $451 ; 555$ \\
\hline *Sumber : ${ }^{1}$ Johnson and Glasser $(2003),{ }^{2}$ Yang et al. $(2007),{ }^{3}$ Gupta et al. $(2008),{ }^{4}$ Zeng et al. $(2010)$,
\end{tabular}

Gambar 2 memperlihatkan bahwa pita pada bilangan gelombang $3441 \mathrm{~cm}^{-1}$ yang melebar dan tajam merupakan gugus fungsi dari hidroksi $(-\mathrm{OH})$. Pita ini dimungkinkan merupakan serapan uluran $\mathrm{OH}$. Serapan tersebut menunjukkan vibrasi antara hidroksi yang berasal dari $\mathrm{H}_{2} \mathrm{O}$ didalam interlayer hydrotalcite. Hal ini sesuai dengan penelitian sebelumnya yang dilakukan oleh Johnson and Glasser (2003); Yang et al. (2007); Gupta et al. (2008); Zeng et al. (2010); Heraldy et al. (2011). Selain itu, pada bilangan gelombang $1629 \mathrm{~cm}^{-1}$ merupakan serapan dari tekukan $-\mathrm{OH}$ pada lapisan hydrotalcite serta serapan dari karbonil ikatan rangkap $\mathrm{C}=\mathrm{O}$ pada anion karbonat $\left(\mathrm{CO}_{3}{ }^{2-}\right)$ (Yang et al., 2007; Gupta et al., 2008 dan Zeng et al. (2010). Kemungkinan lain, menurut Malisova et al. (2018) serapan pada bilangan gelombang $3441 \mathrm{~cm}^{-1}$ dan $1629 \mathrm{~cm}^{-1}$ adalah sebagai penyerap air dalam 
material interlayer dan juga bertindak sebagai representasi interaksi anion karbonat $\left(\mathrm{CO}_{3}{ }^{2-}\right)$ dengan lapisan gugus hidroksi.

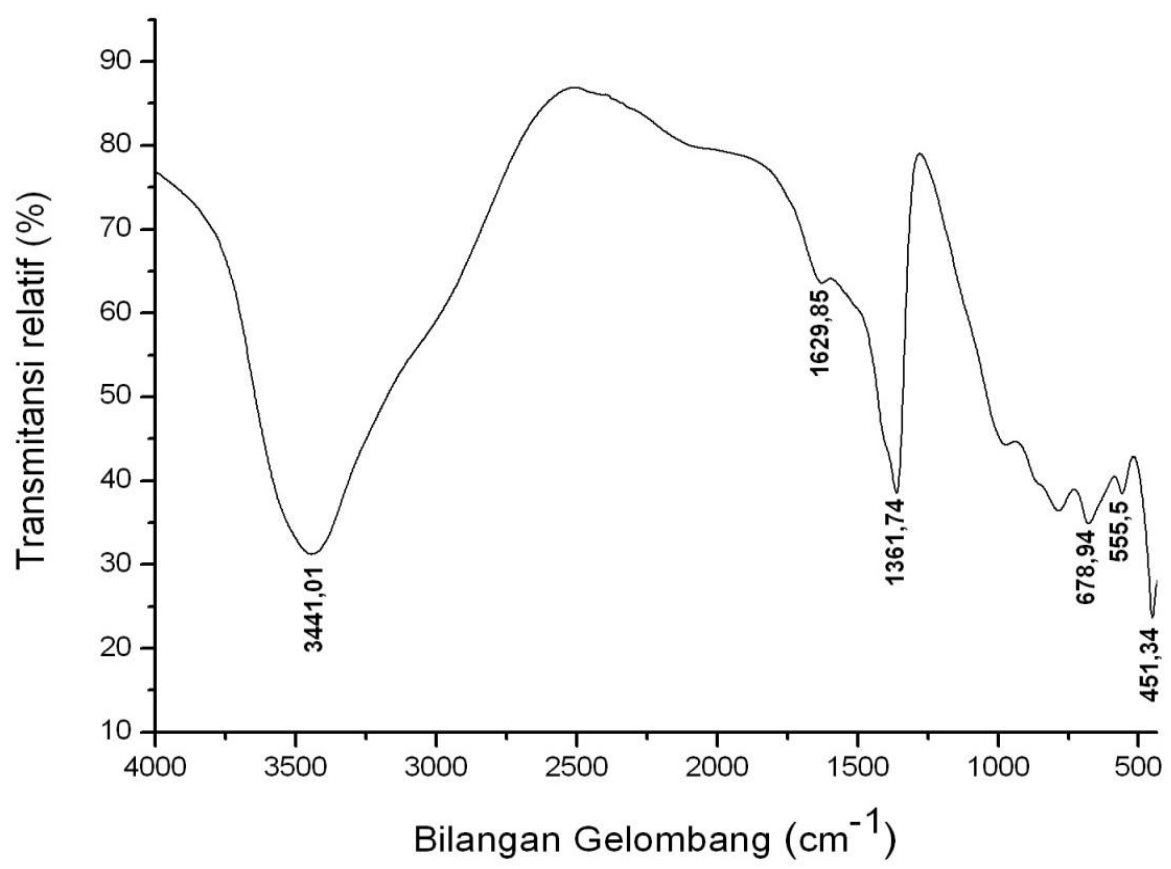

Gambar 2. Spektra FTIR Ca-Mg-Al HTlc hasil sintesis.

Sharma et al. (2007) mengatakan bahwa bilangan gelombang $1370-1384 \mathrm{~cm}^{-1}$ dan 635-663 $\mathrm{cm}^{-1}$ merupakan pita serapan anion penyeimbang karbonat pada interlayer. Pita pada bilangan gelombang $451 \mathrm{~cm}^{-1}$ dapat diartikan sebagai vibrasi ulur $\mathrm{M}-\mathrm{O}$ untuk $\mathrm{M}^{2+}$ $(\mathrm{M}=\mathrm{Mg}, \mathrm{Ca})$, sedangkan pada bilangan gelombang $555 \mathrm{~cm}^{-1}$ sebagai vibrasi ulur $\mathrm{M}-\mathrm{O}$ untuk $\mathrm{M}^{3+}(\mathrm{M}=\mathrm{Al})$. Prikhod'ko et al. (2001) menyebutkan bahwa uluran M-O untuk $\mathrm{M}^{2+}$ berada pada kisaran $396-428 \mathrm{~cm}^{-1}$. Yang et al. (2007) menyebutkan uluran pada $553 \mathrm{~cm}^{-1}$ dapat dikaitkan dengan Al-O. Hasil analisis spektra FTIR menunjukkan adanya gugusgugus fungsi yang dominan menyusun HT. Hal tersebut mengindikasikan bahwa senyawa yang disintesis dari brine water merupakan suatu hydrotalcite-like.

Untuk dapat difungsikan sebagai adsorben, dilakukan analisis luas permukaan (Surface Area Analyzer) pada Ca-Mg-Al HTlc. Tabel 3 berikut menyajikan perbandingan hasil pengukuran luas muka antara Ca-Mg-Al HTlc dengan HT komersial.

Tabel 3. Data perbandingan luas permukaan hasil sintesis $\mathrm{Ca}-\mathrm{Mg}-\mathrm{Al} \mathrm{HTlc}$ dengan HT komersial

\begin{tabular}{cc}
\hline Sampel & Luas permukaan $\left(\mathrm{m}^{2} / \mathrm{g}\right)$ \\
\hline Ca-Mg-Al HTlc hasil sintesis & 110,53 \\
HT Komersial & 7,49 \\
\hline
\end{tabular}


Dari Tabel 3 tampak bahwa Ca-Mg-Al HTlc hasil sintesis memiliki luas muka yang lebih besar dibandingkan dengan luas muka HT komersial. Sharma et al. (2007) menegaskan bahwa Mg/Al HT memiliki luas muka sebesar $62-73 \mathrm{~m}^{2} / \mathrm{g}$. Johnson and Glasser (2003) menyebutkan bahwa luas muka Mg/Al HT adalah 53,9 m²/g. Munoz et al. (2011) mengatakan bahwa HT memiliki luas muka sebesar $70,33 \mathrm{~m}^{2} / \mathrm{g}$. Besarnya luas muka Ca-Mg-Al HTlc hasil sintesis dimungkinkan karena adanya ion kalsium. Ukuran jari-jari ion kalsium yang relatif lebih besar daripada ion magnesium dan alumunium inilah yang berdampak pada luas muka Ca-Mg-Al HTlc hasil sintesis lebih besar. Dengan luas muka yang cukup besar, Ca-Mg-Al HTlc hasil sintesis dapat dimanfaatkan sebagai suatu adsorben.

\section{Penentuan Waktu Kontak Optimum}

Hasil penentuan waktu kontak optimum adsorpsi $\mathrm{Cr}(\mathrm{VI})$ yang dilakukan pada variasi waktu kontak 5, 10, 15, 20, dan 25 menit pada pH 3 tampak seperti pada Gambar 3.

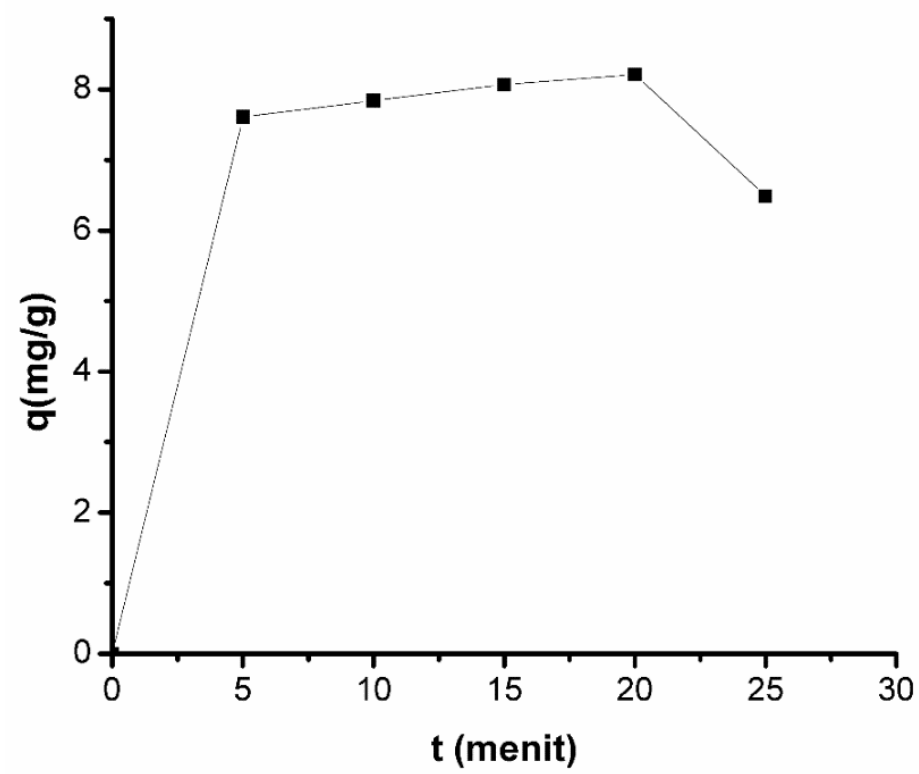

Gambar 3. Pengaruh variasi waktu kontak terhadap kapasitas adsorpsi Cr(VI) oleh HTlc hasil sintesis.

Dari Gambar 3 terlihat bahwa waktu kontak optimum adsorpsi Cr(VI) menggunakan $\mathrm{Ca}-\mathrm{Mg}$-Al HTlc hasil sintesis adalah 20 menit, karena pada saat adsorpsi berlangsung pada menit ke-25, kapasitas adsorpsi mengalami penurunan. Hal ini dapat disebabkan karena waktu kontak yang lama menyebabkan adsorben menjadi jenuh dan kapasitas adsorpsinya pun semakin berkurang, sehingga efisiensi adsorpsinya pun menjadi rendah. Selain itu, diduga bahwa permukaan adsorben dari Ca-Mg-Al HTlc hasil sintesis adalah monolayer dan homogen dengan situsnya yang identik. Kapasitas adsorpsi yang 
terbesar dari Ca-Mg-Al HTlc hasil sintesis adalah sebesar 8,21 mg/g dengan efisiensi adsorpsi mencapai 98,54\%.

\section{Studi Kinetika Adsorpsi}

Kinetika adsorpsi dipelajari pada model persamaan pseudo first order dan pseudo second order. Hasil studi kinetika adsorpsi ini dapat dilihat dalam Gambar 4.

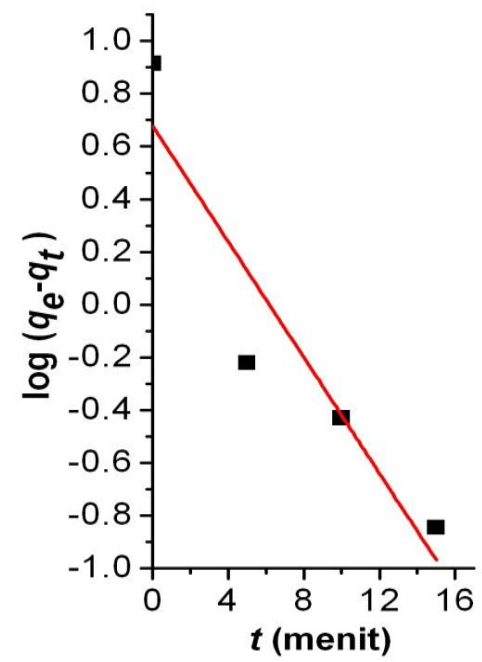

(a)

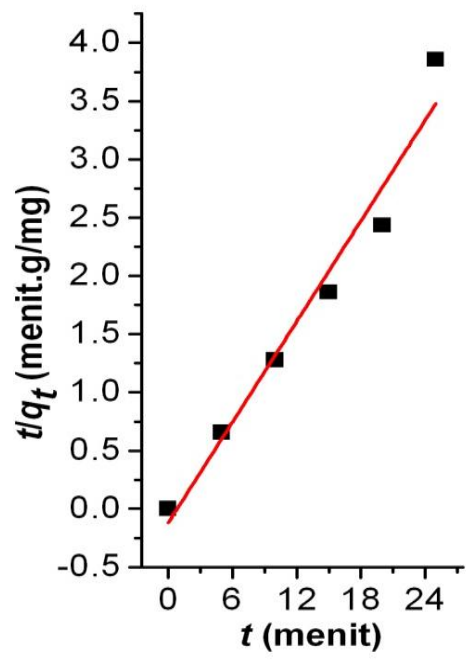

(b)

Gambar 4. Kurva (a) pseudo first order dan (b) pseudo second order pada adsorpsi Cr(VI) menggunakan HTlc hasil sintesis.

Parameter dan besaran kinetika antara Ca-Mg-Al HTlc hasil sintesis dengan HT komersial disajikan dalam Tabel 4.

Tabel 4. Parameter kinetika adsorpsi Cr(VI) oleh HT komersial dan Ca-Mg-Al HTlc hasil sintesis

\begin{tabular}{lcccc}
\hline \multirow{2}{*}{ Adsorben } & \multicolumn{2}{c}{ Pseudo 1 } & \multicolumn{2}{c}{ Pseudo 2 } \\
\cline { 2 - 5 } & $k_{1}$ & $\mathrm{R}$ & $k_{2}$ & $\mathrm{R}$ \\
\hline HT Komersial & 1,3157 & 0,9121 & 0,04309 & 0,89599 \\
HTlc hasil sintesis & 0,25287 & 0,9413 & 0,14398 & 0,9839 \\
\hline
\end{tabular}

Pada Tabel 4, adsorpsi Cr(VI) pada HT komersial mendekati model pseudo first order. Hasil ini sesuai dengan penelitian Manju et al. (1999) serta Lazaridis dan Asouhidou (2003) yang menyebutkan kinetika adsorpsi HT terhadap $\mathrm{Cr}$ (VI) cenderung mendekati pseudo first order. Sedangkan adsorpsi Cr(VI) pada Ca-Mg-Al HTlc hasil sintesis lebih mendekati model pseudo second order yang sesuai dengan penelitian Roto et al. (2009) dan Li et al. (2013). Kapasitas adsorpsi yang terbesar dari HT komersial adalah sebesar 4,19 mg/g dengan efisiensi adsorpsi nya hanya sebesar 50,24\%. Hasil ini lebih kecil dibandingkan dengan $\mathrm{Ca}-\mathrm{Mg}$-Al HTlc hasil sintesis. Hal ini dimungkinkan karena 
surface area HT komersial lebih kecil dibandingkan HTlc hasil sintesis. Proses adsorpsi ini terjadi diduga melalui interaksi elektrostatistik.

\section{Penentuan Isoterm Adsorpsi}

Hasil penentuan isoterm adsorpsi Cr(VI) yang dilakukan dengan variasi konsentrasi awal 50, 75, 100, 125 dan $150 \mathrm{mg} / \mathrm{L}$ pada pH 3 selama 20 menit tampak seperti pada Gambar 5. Pada $\mathrm{pH}$ 3, spesies yang dominan dari $\mathrm{Cr}(\mathrm{VI})$ di dalam larutan adalah ion $\mathrm{HCrO}_{4}{ }^{-}$(Daneshvar et al., 2002). Dengan demikian, proses adsorpsi yang terjadi melalui ikatan kimia antara spesies anion dari $\mathrm{Cr}(\mathrm{VI})$ dengan permukaan $\mathrm{Ca}-\mathrm{Mg}-\mathrm{Al} \mathrm{HTlc}$ yang bermuatan positif.

Bila dilakukan perbandingan antara Ca-Mg-Al HTlc hasil sintesis dengan HT komersial, maka hasil perbandingannya disajikan dalam Tabel 5.

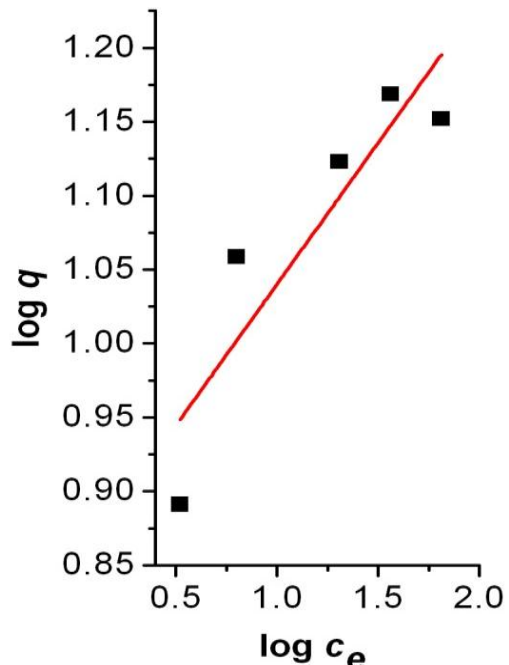

(a)

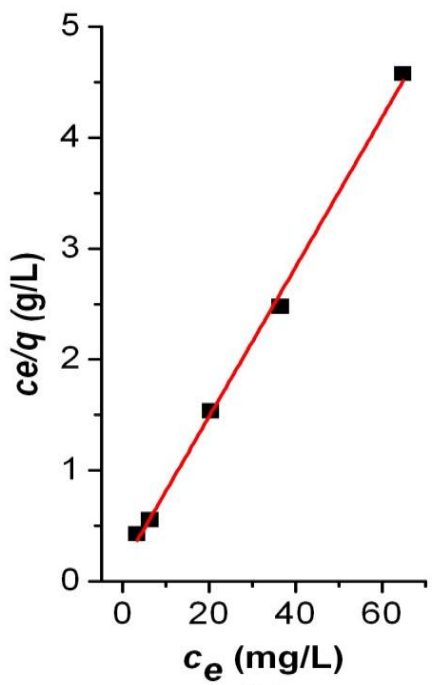

(b)

Gambar 5. Kurva (a) Freundlich dan (b) Langmuir pada adsorpsi $\mathrm{Cr}(\mathrm{VI})$ menggunakan HTlc hasil sintesis.

Tabel 5. Parameter isoterm adsorpsi Cr(VI) oleh HT komersial dan Ca-Mg-Al HTlc hasil sintesis

\begin{tabular}{llccccc}
\hline \multirow{2}{*}{ Adsorben } & \multicolumn{3}{c}{ Langmuir } & \multicolumn{3}{c}{ Freundlich } \\
\cline { 2 - 7 } & Qmax & $k_{L}$ & $\mathrm{R}$ & $k_{F}$ & $n$ & $\mathrm{R}$ \\
\hline HT Komersial & 06,3979 & 0,05261 & 0,5712 & 7,1673 & 14,0056 & 0,0565 \\
HTlc hasil sintesis & 14,8588 & 0,46866 & 0,9989 & 1,5533 & 5,22739 & 0,9032 \\
\hline
\end{tabular}

Pada Tabel 5, adsorpsi Cr(VI) pada HT komersial dan HTlc hasil sintesis samasama mendekati model Langmuir. Hasil ini sesuai dengan penelitian Gutierrez et al. (2009), Xiao et al. (2011) dan Li et al. (2013) yang menyebutkan isoterm adsorpsi HT terhadap $\mathrm{Cr}(\mathrm{VI})$ cenderung mendekati model Langmuir. Dengan mendekati model isoterm Langmuir, dapat diduga bahwa permukaan adsorben dari Ca-Mg-Al HTlc hasil sintesis 
adalah homogen dengan situsnya yang identik. Selain itu, nilai $k_{L}$ dalam kisaran 0-1 sudah menunjukkan bahwa model isotherm Langmuir lebih disukai dari pada model isotherm Freundlich. Kapasitas maksimum yang diperoleh HTlc hasil sintesis lebih besar daripada HT komersial. Hal ini mengindikasikan kemungkinan lebih banyak $\mathrm{Cr}(\mathrm{VI})$ yang terserap dalam HTlc hasil sintesis dibandingkan HT komersial. Hasil studi menunjukkan bahwa CaMg-Al HTlc merupakan salah satu adsorben yang potensial untuk menyerap $\mathrm{Cr}(\mathrm{VI})$ dengan dilakukan perbaikan lebih lanjut di masa yang akan datang.

\section{Karakterisasi Ca-Mg-Al Htlc Hasil Sintesis Sebelum dan Sesudah Adsorpsi}

Untuk mengetahui apakah $\mathrm{Cr}(\mathrm{VI})$ telah terserap pada adsorben $\mathrm{Ca}-\mathrm{Mg}-\mathrm{Al} \mathrm{HTlc}$, maka dilakukan analisis FTIR pada adsorben yang digunakan setelah proses adsorpsi $\mathrm{Cr}(\mathrm{VI})$. Grafik perbandingan spektra FTIR adsorben (Ca-Mg-Al HTlc hasil sintesis) sebelum dan setelah adsorpsi ditunjukkan pada Gambar 6.

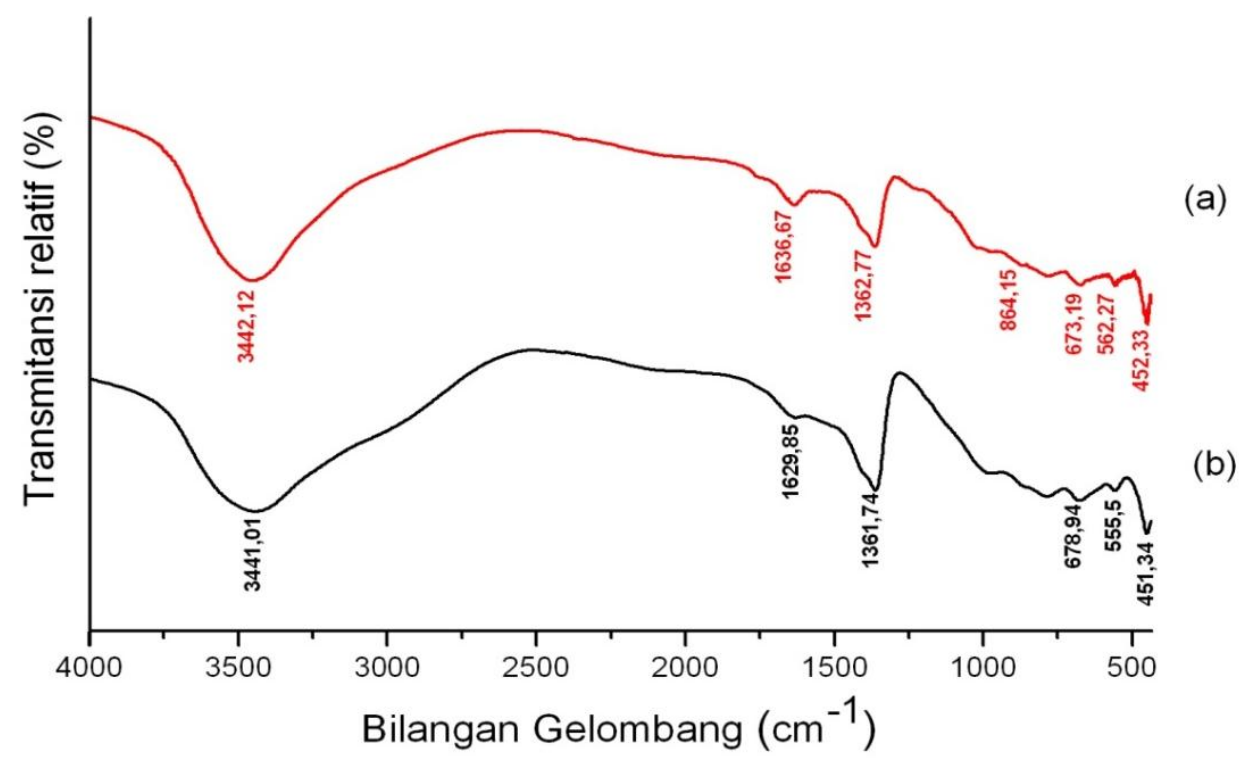

Gambar 6. Perbandingan spektra FTIR HTlc hasil sintesis saat (a) setelah dan (b) sebelum adsorpsi $\mathrm{Cr}(\mathrm{VI})$

Gambar 6 memperlihatkan adanya pergeseran bilangan gelombang pada kisaran $400-4000 \mathrm{~cm}^{-1}$ antara pita spektra sebelum dan sesudah adsorpsi $\mathrm{Cr}(\mathrm{VI})$. Hal ini menandakan adanya perubahan pada $\mathrm{Ca}-\mathrm{Mg}-\mathrm{Al} \mathrm{HTlc}$ hasil sintesis setelah proses adsorpsi $\mathrm{Cr}(\mathrm{VI})$ berlangsung. Perubahan ini menunjukkan terserapnya ion kromium dalam $\mathrm{Ca}-\mathrm{Mg}$ Al HTlc hasil sintesis. Holman et al. (1999) menyebutkan daerah spektra untuk Cr(VI) berkisar pada $800-900 \mathrm{~cm}^{-1}$. Li et al. (2009) menjelaskan bahwa adanya puncak di 884 $\mathrm{cm}^{-1}$ menandakan adanya pertukaran ion dalam interlayer dengan ion $\mathrm{HCrO}_{4}^{-}$. Xiao et al. (2011) juga menyebutkan bahwa pita spektra yang muncul pada $876-885 \mathrm{~cm}^{-1}$ menandakan adanya ikatan $\mathrm{Cr}-\mathrm{O}$ pada adsorben yang mengadsorpsi $\mathrm{Cr}(\mathrm{VI})$. Hal ini membuktikan 
bahwa adanya pita spektra pada $864 \mathrm{~cm}^{-1}$ dimungkinkan merupakan serapan dari ion kromium.

\section{KESIMPULAN}

Hasil dari penelitian ini menunjukkan bahwa senyawa hasil sintesis hydrotalcitelike dari brine water merupakan $\mathrm{Ca}-\mathrm{Mg}$-Al hydrotalcite-like. Kinetika adsoprsi $\mathrm{Cr}(\mathrm{VI})$ oleh $\mathrm{Ca}-\mathrm{Mg}-\mathrm{Al}$ HTlc hasil sintesis mengikuti persamaan kinetika pseudo second order dan isoterm adsorpsinya mengikuti model isoterm Langmuir. Kapasitas adsorpsi yang diperoleh adalah 6,3979 mg/g untuk adsorben HT komersial dan 14,8588 mg/g untuk adsorben Ca$\mathrm{Mg}-\mathrm{Al}$ hydrotalcite-like.

\section{DAFTAR PUSTAKA}

Anirudhan, T.S. and Suchithra, P.S., 2010. Equilibrium, Kinetic and Thermodynamic for The Adsorption of Heavy Metal Onto Chemically Modified Hydrotalcite. Indian Journal of Chemical Technology 17, 247-259.

Cavani, F., Trifiro, F., and Vaccari, A., 1991. Hydrotalcite- type anionic clays preparation, properties and applications. Catalysis Today 11, 173-301.

Daneshvar, N., Salari, D., and Aber, S., 2002. Chromium Adsorption and Cr(VI) Reduction to Trivalent Chromium in Aqueous Solutions by Soya Cake. Journal of Hazardous Materials 94, 49-61.

Gao, L., Xu, B., Xiao, G., and Jianhua, L., 2010. Biodiesel Sythesis Catalyzed by the KF/Ca-Mg-Al Hydrotalcite Base Catalyst. Energy Fuels 24, 645-651.

Gupta, S., Agarwal, D.D., and Banerjee, S., 2008. Synthesis and Characterization of Hydrotalcite: Potential Thermal Stabillizer PVC. Indian Journal of Chemistry 47A, 1004-1008.

Gutierrez, N., Ramos, E., and Contreras, C., 2009. Removal of Chromium (VI) from Aqueous Solutions by Hydrotalcite-Like Compounds: Kinetic and Equilibrium Studies. Revista Mexicana De Fisica 55 (1), 135-138.

Heraldy, E., Triyono, Santosa, S.J., and Wijaya, K., 2011. Mg/Al Hydrotalcite-like Synthesized from Brine Water for Eosin Yellow Removal. Indonesian Journal of Chemistry 11 (2), 117-123.

Heraldy, E., Prasasti, D., Wijaya, K., Santosa S.J., and Triyono, 2012a. Studi Pendahuluan Pemanfaatan Limbah Desalinasi untuk Pembuatan Mg/Al Hydrotalcite-Like sebagai Adsorben Methyl Orange. Jurnal Bumi Lestari 12, 16-23.

Heraldy, E., Nurcahyo, I. F., dan Ainurofiq, A., 2012b. Pembuatan Senyawa Hydrotalcitelike dari Brine Water untuk eksipien Industri Farmasi. Prosiding Insentif Riset SINas, 29-30 November 2012. ISBN : 978-602-18926-2-6.

Heraldy, E., Santosa, S.J., Triyono, and Wijaya, K., 2015. Anionic and Cationic Dyes Removal from Aqueous Solutions by Adsorption Onto Synthetic Mg/Al Hydrotalcite-Like Compound. Indonesian Journal of Chemistry 15 (3), 234-241. 
Heraldy, E., Nugrahaningtyas, K.D., and Heriyanto, 2017. Kalsinasi Ca-Mg-Al Hydrotalcite dari Brine Water dan Karakterisasinya. AlChemy Jurnal Penelitian Kimia 13 (2), 205-216.

Ho, Y.S., 2005. Effect of pH on Lead Removal from Water Using Tree Fern As The Sorbent. Bioresources Technology 96, 1292-1296.

Holman, H.N., Perry, D.L., Martin, M.C., Lamble, M.G., McKinney, W.R., and HunterCevera, J.C., 1999. Real Time Characterization of Biogeochemical Reduction of Cr(VI) on Basalt Surfaces by SR-FTIR imaging. Geomicrobiology Journal 16, $307-$ 324.

Johnson, C.A., and Glasser, F.P., 2003. Hydrotalcite-Like Minerals in The Environment: Synthesis, Characterization and Thermodynamic Stability. Clays and Clay Minerals 51, 1-8.

Kameda, T., Yoshioka, T., Uchida, M., and Okuwaki, A., 2000. Synthesis of Hydrotalcite using Magnesium from Seawater and Dolomite. Molecular Crystal and Liquid Crystal 341, 407-412.

Lazaridis, N.K., and Asouhidou, D.D., 2003. Kinetics of Sorptive Removal of Chromium (VI) from Aqueous by Calcined $\mathrm{Mg}-\mathrm{Al}-\mathrm{CO}_{3}$ Hydrotalcite. Water Research 37, 2875-2882.

Li, Y., Wang, J., Li, Z., Liu, Q., Liu, L., Zhang, X., and Yu, J., 2013. Ultrasound Assisted Synthesis of Ca-Al Hydrotalcite for U(VI) and $\mathrm{Cr}(\mathrm{VI})$ Adsorption. Chemical Engineering Journal 218, 295-302.

Mališová, M., Horňáček, M., Mikulec, J., Hudec, P., and Jorík, V., 2018. FTIR Study of Hydrotalcite. Acta Chimica Slovaca 11 (2), 147-166.

Manju, G.N., Gigi, M.C., and Anirudhan, T.S., 1999. Hydrotalcite as A Adsorbent for Removal of Chromium (VI) from Aqueous Media: Equilibrium Studies. Indian Journal of Chemical Technology 6, 134-141.

Munoz, B.E.L., Robles, R.R., Garcia, J.L.I., and Guiterrez, M.T.O., 2011. Adsorption of Basic Chromium Sulfate Used in Tannery Industries by Calcines Hydrotalcite. Journal Mexico Chemistry Society 55(3), 37-141.

Prikhod'ko, R.V., Sychev, M.V., Astrelin, I.M., Erdmann, K., Mangel, A., and Van Santen, R.A., 2001. Synthesis and Structural Transformations of Hydrotalcite-like Materials Mg-Al and Zn-Al. Russian Journal of Applied Chemistry 74(10), 16211626.

Roto, Nindiyasari, F., and Tahir, I., 2009. Removal of Hexacyanoferrate(II) Using Zn-AlOAc Hydrotalcite as an Anion Exchanger. Journal of Physical Science 20(2), 7384.

Setshedi, K., Ren J., Aoyi, O., and Onyago, M.S., 2012. Removal of Pb(II) from Aqueous Solution Using Hydrotalcite-like Nanostructured Material. International Journal of the Physical Sciences 7(1), 63-72.

Sharma, K.S, Kuswhwaha, P.K., Srivastava, V.K., Bhatt, S.D., and Jasra, R.V., 2007. Effect of Hydrothermal Conditions on Structural and Textural Properties of Synthetic Hydrotalcites of Varying $\mathrm{Mg} / \mathrm{Al}$ Ratio. Industrial and Engineering Chemistry Research 46(14), 4856-4865.

Yang, Z.Q.., Choi, K.M., Jiang, N.Z., dan Park, S., 2007. Microwave Synthesis of 
Hydrotalcite by Urea Hydrolysis, Bulletin of the Korean Chemical Society 28 (11), 2029-2033.

Yang, D., Song, Z., and Qian, X., 2010. Adsorption of Benzoic Acid and Their Calcined Products. Environmental Engineering Science 27, 853-860.

Xiao, L., Ma, W., Han, M., and Cheng, Z., 2011. The Influence of Ferric Iron In Calcined Nano-Mg/Al Hydrotalcite on Adsorpstion of $\mathrm{Cr}(\mathrm{VI})$ from Aqueous Solution. Journal of Hazardous Materials 186, 690-698.

Zeng, H., Wang, Y., Feng, Z., You, K., Zhao, C., Sun, J., and Liu, P., 2010. Synthesis of Propylene Glycol Monomethyl Ether Over Mg/Al Hydrotalcite Catalyst. Catalyst Letter 137, 94-103. 